\title{
Geochemical characterization of the new 2018-2019 Mayotte submarine
}

\author{
EDWARD INGLIS ${ }^{1}$, PAMELA GUTIERREZ ${ }^{2}$, TU-HAN \\ LUU $^{2}$, PIERRE BURKEL ${ }^{3}$, PASCALE BESSON ${ }^{3}$ AND \\ CATHERINE CHAUVEL ${ }^{4}$
}

${ }^{1}$ Université de Paris, Institut de physique du globe de Paris, CNRS/UMR 7154

${ }^{2}$ Université de Paris - IPGP - CNRS/UMR 7154

${ }^{3}$ Université de Paris - Institut de physique du globe de Paris CNRS

${ }^{4}$ Université de Paris, Institut de Physique du Globe de Paris, CNRS UMR 7154

Presenting Author: inglis@ipgp.fr

Since spring 2018 an ongoing seismic crisis has unfolded in Mayotte, the eastern most island of the Comoros volcanic archipelago, which consists of the islands of Grande Comore, Anjouan, Moheli and Mayotte, and is located between Africa and Madagascar. The origin of the seismicity is due to intense volcanic activity along a ridge east of the island. At the end of this ridge, $\sim 50 \mathrm{~km}$ east of Mayotte, a new $800 \mathrm{~m}$-high volcanic edifice formed between 2018-2019. Here we present new geochemical and isotopic data for samples collected through several dredges both on the new volcanic edifice and other volcanic structures located along the ridge.

Samples have major element compositions consistent with an alkaline series, ranging from tephrite to phonolite. The radiogenic isotope compositions are tightly clustered for $\mathrm{Sr}$ and $\mathrm{Nd}\left({ }^{87} \mathrm{Sr} /{ }^{86} \mathrm{Sr}=0.703350\right.$ and $\left.{ }^{143} \mathrm{Nd} /{ }^{144} \mathrm{Nd}=0.512817\right)$ and correspond to the least radiogenic data published for Mayotte. A key feature of the trace element data for the recent volcanics is their striking enrichment in $\mathrm{Ba}$ (positive anomaly and $\mathrm{Ba} / \mathrm{Th}>250)$ and their elevated $\mathrm{Ce} / \mathrm{Pb}(>60)$. Although the origin of such peculiarities is unclear at this stage, it remains that high $\mathrm{Ce} / \mathrm{Pb}$ is often found in basalts with HIMU characteristics.

The data on the new volcano stand in sharp contrast with the published data for the Comoros archipelago. While both lavas from Grande Comore and Mayotte display a relatively large range of isotopic compositions in $\mathrm{Sr}$ and $\mathrm{Nd}$ space, this is not the case of the new volcano. Previous models for the origin of volcanism in the area have invoked both plume and melting of the lithospheric mantle. However, given the contrasting ages for the four islands within the archipelago it is unlikely that a simple linear plume migration can account for the melting. Furthermore, Mayotte represents the oldest volcanic center of the four islands (initial volcanism dates from 15-10 Ma), precluding a linear migration of the plume over time. While the exact origin of melting for this new volcano remains elusive at this time, it is clear that the $\mathrm{Sr}$ and $\mathrm{Nd}$ isotope data indicate tapping of a distinctive source region. 